\title{
Key Points of Inspection, Appraisal and Reinforcement Design for a Masonry Structure Reconstruction Project
}

\author{
Zhang $\mathrm{Wei}^{1^{*}}$ \\ ${ }^{1}$ Shandong Water Conservancy Vocational College, Rizhao City, Shandong, 276826, China
}

\begin{abstract}
In order to solve the problems in the reconstruction of masonry structure, this article combines the actual situation of a certain masonry structure building, analyzes its inspection and identification and reconstruction and reinforcement design, and proposes the key points of the reinforcement design, in order to provide references for relevant personnel to ensure the smooth implementation of the project and realize it the expected transformation goals.
\end{abstract}

\section{INTRODUCTION}

Masonry structure buildings are rare now, and most of the existing masonry structure buildings were built over a long period of time. These masonry structures need to be transformed in order to meet the functional requirements. In the actual transformation process, the inspection and appraisal should be done first, and then based on the results of the inspection and appraisal, a reasonable and feasible reinforcement design plan should be formulated, and the key points in the plan should be clarified to provide a reliable reference for the actual reinforcement and transformation.

\section{ENGINEERING PROFILE}

A building was built in the early 1980s with a brick-concrete structure, 7 floors above the ground, prefabricated slabs, and strip foundations. According to Category $\mathrm{C}$ seismic fortification, it will be appraised with a 30-year follow-up service life. The standard floor of the building is a regular rectangle, but there is a door bucket of about $53 \mathrm{~m} 2$ on the first floor above the ground. The size of the standard layer is length $\times$ width $=61.2 \mathrm{~m} \times 13.6 \mathrm{~m}$, and the height of the standard layer is $3 \mathrm{~m}$. The height difference between indoor and outdoor is $0.45 \mathrm{~m}$, the total height of the building is $21.45 \mathrm{~m}$, and the total construction area is about $5880 \mathrm{~m} 2$.

\section{Testing}

After testing, it is found that there are cracks on the outer walls and part of the inner transverse walls on the top two sides of the main structure of the building. The cracks are temperature shrinkage cracks, and the maximum width can reach $1.4 \mathrm{~mm}$. The actual layout of the building's structural columns and ring beams can meet the requirements of relevant standards. Mixed mortar is used on the first to seventh floors above the ground, and the strength of the mortar used on different floors is different. Among them, the strength of the mortar used in the first layer above the ground is $1.6 \mathrm{MPa}$. The strength of the mortar used in the second layer above the ground is 1.3 $\mathrm{MPa}$. The strength of the mortar used in the 3rd to 6th layer above the ground is $1.4 \mathrm{MPa}$. The strength of the mortar used in the 7 th layer above the ground is $5.6 \mathrm{MPa}$. The strength of sintered bricks used in construction is MU15. The results of testing the actual compressive strength of concrete members are as follows.

The strength of the mortar used in the first layer above the ground is 1.6 MPa. The strength of the mortar used in the second layer above the ground is $1.3 \mathrm{MPa}$.

The strength of the mortar used in the 3rd to 6th layer above the ground is $1.4 \mathrm{MPa}$.

The strength of the mortar used for the seventh layer above the ground is $5.6 \mathrm{MPa}$.

The strength of sintered bricks used in construction is MU15. The results of testing the actual compressive strength of concrete members are shown in table 1.

TABLE 1 TEST RESULTS OF COMPRESSIVE STRENGTH OF MASONRY STRUCTURAL MEMBERS ON EACH FLOOR OF THE BUILDING

\begin{tabular}{|c|c|c|c|}
\hline No. & Layer & $\begin{array}{c}\text { Compressive } \\
\text { strength of ring } \\
\text { beam }\end{array}$ & $\begin{array}{c}\text { Compressive } \\
\text { strength of } \\
\text { structural } \\
\text { column }\end{array}$ \\
\hline 1 & First & $15.5 \mathrm{MPa}$ & $15.2 \mathrm{MPa}$ \\
\hline 2 & Second & $15.2 \mathrm{MPa}$ & $14.6 \mathrm{MPa}$ \\
\hline 3 & Third & $14.7 \mathrm{MPa}$ & $14.2 \mathrm{MPa}$ \\
\hline 4 & Fourth & $15.2 \mathrm{MPa}$ & $14.7 \mathrm{MPa}$ \\
\hline 5 & Fifth & $15.0 \mathrm{MPa}$ & $15.1 \mathrm{MPa}$ \\
\hline 6 & Sixth & $15.3 \mathrm{MPa}$ & $15.4 \mathrm{MPa}$ \\
\hline 7 & Seventh & $14.6 \mathrm{MPa}$ & $16.2 \mathrm{MPa}$ \\
\hline
\end{tabular}

The compressive strengths of the ring beams and structural columns of the first layer above the ground are 15.5 $\mathrm{MPa}$ and 15.2MPa, respectively. The compressive 
strengths of the ring beams and structural columns of the second layer above the ground are $15.2 \mathrm{MPa}$ and $14.6 \mathrm{MPa}$, respectively. The compressive strengths of the ring beams and structural columns of the third layer above the ground are 14.7 $\mathrm{MPa}$ and $14.2 \mathrm{MPa}$, respectively. The compressive strengths of the ring beams and structural columns of the fourth layer above the ground are 15.2MPa and 14.7MPa, respectively. The compressive strengths of the ring beams and structural columns of the fifth layer above the ground are $15.0 \mathrm{MPa}$ and $15.1 \mathrm{MPa}$ respectively. The compressive strengths of the ring beams and structural columns of the sixth layer above the ground are 15.3MPa and 15.4MPa, respectively. The compressive strengths of the ring beams and structural columns of the seventh layer above the ground are 14.6 $\mathrm{MPa}$ and 16.2 $\mathrm{MPa}$, respectively.

Based on various test data, the carrying capacity check calculation is carried out with the help of numerical analysis software [1]. Empirical calculations show that the compressive bearing capacity of the local wall of the building cannot meet the requirements. In the process of reinforcement design, it is necessary to focus on this aspect, improve the bearing capacity of the structure through reasonable and feasible reinforcement treatment, and effectively repair the existing cracks [2].

In this regard, the following transformation plans are formulated.

The first is to remove the existing door bucket on the first floor above the ground, and add a hall in the middle of the north side, the area of the hall is about $145 \mathrm{~m} 2$.

Then, two newly installed passenger elevators are located on both sides of the inside of the hall, adjacent to the original building.

Two new decorative walls are newly installed, which are located on both sides of the entrance hall, forming a whole with the original structure.

Install a new integral bathroom in all rooms with an area of about $4 \mathrm{~m} 2$. At the same time, move the door opening in the middle of the wall section to one end of the wall section in the room.

Next, it can set up a new water tank room on the top floor of the building with an area of about $76 \mathrm{~m} 2$.

Solar collectors are added on both sides of the top water tank.

\section{REINFORCED DESIGN}

There are many places to be renovated in the building, and the original structure of the building needs to be greatly modified. In this regard, it is necessary to fully consider the inspection and appraisal results, and combine the drawings after the completion of the transformation to apply the load, and do the bearing capacity check [3]. In actual work, the reinforcement design should be completed according to the characteristics of the building, combined with various functional requirements and related technical specifications.

\subsection{Design Discipline}

During the reinforcement design process, the following basic principles should be strictly followed.

- In the process of rebuilding the masonry structure, the newly added load should be reduced as much as possible to prevent the lower bearing capacity of the original structure or the lack of sufficient bearing capacity of the substructure.

- When designing the reinforcement of the masonry structure, it is necessary to fully consider the possible impact of the secondary force. Before starting the reinforcement, the concrete member itself has cracked or deformed. After the reinforcement is completed, the original concrete member and the reinforcement material are stressed at the same time [4].

- Reinforcement of masonry structures shall fully consider the integrity of the structure. When strengthening the connection between different components, it is necessary to ensure that the actual distribution of structural rigidity and bearing capacity is reasonable, and to avoid damage due to stress concentration in the structure.

\subsection{Reinforcement Plan}

The specific content of the building's reinforcement plan is as follows.

For wall cracks, they are identified as temperature shrinkage cracks, their width exceeds $0.5 \mathrm{~mm}$, and the crack depth is also very large. In this regard, the design adopts pressure grouting method to deal with. For the selection of grouting material, cement-based grouting material that does not shrink is the main choice. In addition, the cracked wall of the building has poor seismic resistance, so it needs to be reinforced by adding a surface layer. It should be noted that cracks must be repaired before the surface layer is added [5].

For walls bearing capacity can no longer meet the requirements, they should be reinforced in time. The building is going to continue to be used for 30 years. In the process of carrying out the calculation of the bearing capacity according to the various test data, the economical efficiency should be fully considered in the reinforcement design and optimization, and the live load should be appropriately reduced. Relevant results show that the actual bearing capacity of the wall cannot meet the requirements. Among them, the ratio of seismic resistance to effect is in the range of $0.55-0.97$. The ratio of resistance to compression to effect is in the range of 0.50-0.99, which cannot meet the standard requirements. In this regard, the design decided to adopt the method of setting a surface layer for reinforcement treatment, and the thickness of the surface layer is controlled according to $60 \mathrm{~mm}$. Through such reinforcement treatment, the rigidity of the wall and the bearing capacity in both horizontal and vertical directions can be improved (where the horizontal bearing capacity is the shear bearing capacity and the vertical bearing capacity is the compressive bearing capacity). The wall of the building's stairwell adopts a non-floor supporting type, the wall of 
this part. Its free height is relatively large, resulting in insufficient shear resistance, and two surface layers are required for reinforcement [6].

- In accordance with the requirements of the architectural design, the structure of the newly-added entrance hall adopts a frame form. In order to have a good structural integrity and try to prevent the production of a mixed structural system, the two newly installed elevators have exactly the same structural form, and at the same time, the lateral rigidity level is improved through the appropriate setting of supports. In order to minimize the adverse impact that the new structure may have on the original structure, it is necessary to form two separate buildings through a reasonable setting of the partition between the two. For the water tank set on the top floor of the building, its structure is a masonry structure, and the newly added part and the original structure wall should be aligned up and down. In order to reduce the impact of the noise between the water tanks on the normal use of the room, the sound insulation layer should also be reasonably set. That is, the distance between the water tanks is raised $0.7 \mathrm{~m}$ from the ground surface. Because the height of the sound insulation layer is relatively low, the floor design between the water tanks uses profiled steel plates (figure 1) to form a combined floor [7]. Among them, in addition to being used as a floor slab, the profiled steel plate can also be used as a formwork system in the pouring construction, but it does not need to be removed after the pouring construction is completed.

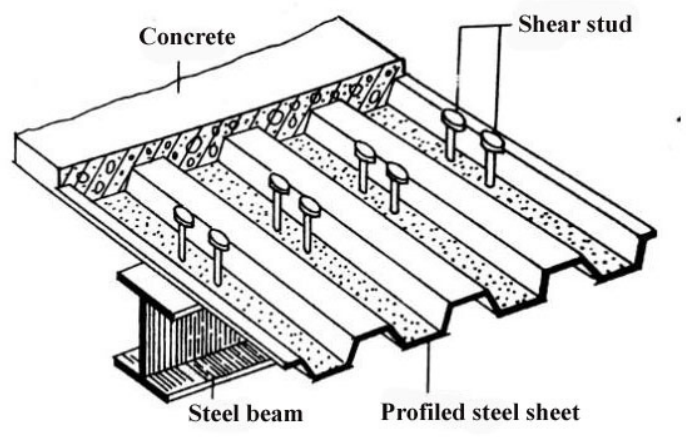

Figure 1 Compressed steel plate

- The building uses cast-in-place slab stairs, and the strength of the concrete used can reach $13 \mathrm{MPa}$. It can be obtained by software calculation that the bearing capacity of the floor slab is low, and reinforcement treatment is also needed. Considering that the strength of the original structure should reach $\mathrm{C} 15$ or more, the method of sticking carbon fiber cloth is used for reinforcement. Therefore, this method cannot be used in the building, and the stairs should be effectively reinforced by increasing the cross section.
- According to the basic requirements of architectural design, the door opening in the middle of the wall section in the room should be moved to one end of the wall section. The original opening is sealed first, and the floor where the strength of the mortar is less than $2.5 \mathrm{MPa}$ is sealed by groove-and-groove masonry, and the floor with the strength of the mortar above $2.5 \mathrm{MPa}$ is sealed by chemical reinforcement. After the hole is sealed, a new door hole is drilled in the required position. If the size of the opening exceeds $2.1 \mathrm{~m}$, it is necessary to add structural columns on both sides of the opening. For newly-added structural columns, they need to be connected to the lower ring beams by planting reinforcement.

- In each room, it can set up a new overall bathroom, and set up water, electricity and heating pipes. If the opening is larger, it will cause greater damage to the prefabricated floor. It is necessary to replace the floor slabs that need openings with cast-in-place slabs to play an effective role in reinforcement. Through on-site investigations, four prefabricated panels should be replaced. The replaced cast-in-place slab adopts three-sided simply supported form. The roof support should be strengthened during construction. Two adjacent rooms cannot be demolished at the same time, but alternate construction.

- $\quad$ There are some sprinkler pipes on the top floor of the building that need to pass through the ring beams. To avoid damage to the integrity of the building structure itself, steel tie rods can be used to replace the damaged ring beams. The diameter and size of the steel tie rods can be determined based on the thickness of the wall and the strength of the mortar. During the construction process, the steel tie rods must be tightened to avoid bending and sagging. In addition, all exposed iron parts should be evenly painted with a layer of anti-rust paint [8].

- In order to make the structure have a good integrity, the effective length of the floor support should be increased appropriately. For the part of the wall reinforced with the surface layer, the surface layer can increase the effective length of the prefabricated slab itself. The vertical steel bar passing through the floor slab has basically the same function as the anchor bolt. For walls that have not been reinforced, long angles can be added to the connection between the wall and the prefabricated slab to increase the effective length of the support for the slab itself [9]. In addition, it is necessary to stick carbon fiber cloth along the horizontal and vertical directions at the bottom of the board to improve the bearing capacity while ensuring durability. 
- The foundation of the building adopts a strip foundation with a buried depth of $1.7 \mathrm{~m}$, and the height difference between the indoor and outdoor parts of the foundation is $0.45 \mathrm{~m}$. The minimum distance between the top of the foundation and the ground is $0.36 \mathrm{~m}$. Therefore, a large load has been added to the reconstruction, so the original foundation can no longer meet the requirements, and the foundation needs to be strengthened. Because the distance between the top surface of the foundation and the ground is very small, in order to facilitate subsequent pipeline installation and maintenance, it is not recommended to transform the entire original foundation into a raft foundation. Reinforced concrete sleeves can be used to widen the brick strips.

\section{ConcLusion}

To sum up, by testing the compressive strength of the masonry structure of the project to be renovated, with the help of numerical analysis software to implement the bearing capacity check calculation, it is determined that the bearing capacity of the masonry structure meets the requirements, so as to provide a reference for the targeted reinforcement design. Combined with the actual situation of a certain masonry structure building, on the basis of comprehensive consideration of the safety of the building structure and the rationality and economy of the reconstruction, a detailed reconstruction plan was compiled based on the results of the inspection and appraisal of the building structure. Based on past engineering experience and related technical specifications, the specific ideas for the preparation of the reinforcement plan are clarified, and the various reinforcement content and methods involved can provide reference for similar projects.

\section{REFERENCES}

1. Li Hemei, Lin Shuanggen. Research on the detection, identification and reinforcement design of a masonry structure renovation project J. Low Temperature Building Technology, 2020, 42(01): 128-130+134.

2. Xia Guanglu, Li Junjie. On the inspection, identification and reinforcement of masonry structure after fire J. Engineering Quality, 2019, 37(12): 73-75+79.

3. Zhang Yijing, Wu Longfei, Zhang Fan, Gao Shixiong, Liu Jia. Parametric application of BIM technology in the field of inspection and identification of existing brick masonry structures J. Low Temperature Construction Technology, 2019, 41(11): 124-127.

4. Wu Xiaojing. The role of structural columns in masonry structures and related problems may be encountered during structural identification J. Fujian Building Materials, 2018, 10(06): 19-20.

5. Song Beibei, Wei Changbao, Zhang Haiyan. Exploration and identification of a masonry structure teaching building without survey design J. Gansu Metallurgy, 2018, 40(03): 108-112.

6. Deng Jinshang. Key issues in seismic detection, identification and reinforcement of existing masonry structures J. Building Materials and Decoration, 2016, 10(50): 173-174.

7. Zhang Minqiang, Liu Baodong, Li Yuzhong, Yang Shuzhen, Feng Wenwen. Safety and seismic detection and appraisal of typical rural masonry structures J. Seismic Engineering and Reinforcement, 2016, 38(03): 124-129.

8. Qin Wen. Inspection and identification of existing old masonry structure houses in cities under multiple disasters[J]. Shanxi Architecture, 2016, 42(01): 144-145+254.

9. Wang Gang. Detecting the strength of masonry mortar and the appraisal analysis of masonry structure by using mortar sheet local compression method J. Building Technology, 2015, 46(S2): 192-193. 